\title{
Large Cardiac Fibroma - a Case Report of Sudden Death in a 10-year-old Child
}

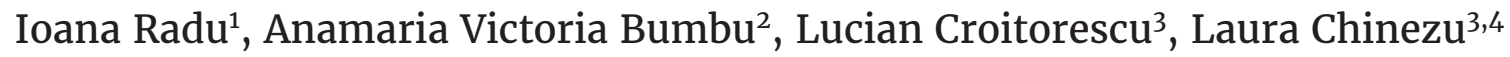 \\ ${ }^{1}$ University of Medicine and Pharmacy, Tîrgu Mureș, Romania \\ ${ }^{2}$ Department of Plastic Surgery, Emergency County Hospital, Oradea, Romania \\ ${ }^{3}$ Forensic Medicine Institute, Tîrgu Mureș, Romania \\ ${ }^{4}$ Department of Histology, University of Medicine and Pharmacy, Tîrgu Mureș, Romania
}

\section{ABSTRACT}

Introduction: Cardiac fibroma is a rare benign tumor, although it is considered the second most frequent cardiac tumor in children. It is located in the ventricular myocardium, frequently in the interventricular septum. One third of the cases are asymptomatic, being discovered postmortem. Case presentation: A 10-year-old male child accused severe dyspnea a few minutes before its sudden death. Autopsy examination revealed hypertrophic cardiomegaly, the entire left ventricular wall being replaced by an enlarged tumor mass. On histopathological examination, the tumor was diagnosed as cardiac fibroma. Conclusions: Noninvasive examinations during childhood, such as cardiac ultrasound, increase the early detection of the tumors of the heart, decreasing the number of sudden death cases in young patients, especially children.

Keywords: cardiac fibroma, tumor, sudden death, young patient

\section{ARTICLE HISTORY}

Received: June 26, 2018

Accepted: August 3, 2018

\section{CORRESPONDENCE}

\section{Ioana Radu}

Str. Aleea Carpați nr. 33, sc. E, ap. 96 540318 Tîrgu Mureș, Romania Tel: +40 748128889

E-mail: ioanaradu888@gmail.com

\section{INTRODUCTION}

Cardiac tumors are very rare in both adults and children. From all cardiac tumors, primary lesions have an incidence of $5 \%$, and secondary lesions (metastases) occur in $95 \%$ of cases..$^{1-3}$ The frequency of primary cardiac tumors varies between $0.0017 \%$ and $0.33 \%$ in clinical studies, and between $0.002 \%$ and $0.1 \%$ in necropsy studies. ${ }^{3-5}$ Most cardiac tumors are benign (approximately $75 \%$ ), the most common being myxoma in adults $(40 \%)$ and rhabdomyoma in children $(40-60 \%))^{3,6-9}$ Cardiac fibroma is the second most frequent benign tumor of the heart in children (about $12-16 \%$ ), with an increased prevalence in those with Gorlin syndrome. ${ }^{3,10-13}$
Cardiac tumors can occur both during fetal and postnatal life. Clinical manifestations during fetal life include arrhythmia and congestive heart failure. ${ }^{9}$ In postnatal life, the symptoms of cardiac tumors are characterized by a reduced-specificity polymorphism, the clinical picture revealing changes in the general condition with fever, weight loss, obstruction at opening and closing of the valve, obstruction of ventricular filling or emptying, atrial or ventricular arrhythmia with atrioventricular conduction disorders, pulmonary or systemic thromboembolism, fluid pericarditis. In most cases, cardiac tumors are asymptomatic, being accidentally discovered on ultrasound, computed tomography, thoracic magnetic resonance, or in unfortunate cases only during autopsy. ${ }^{3}$ 

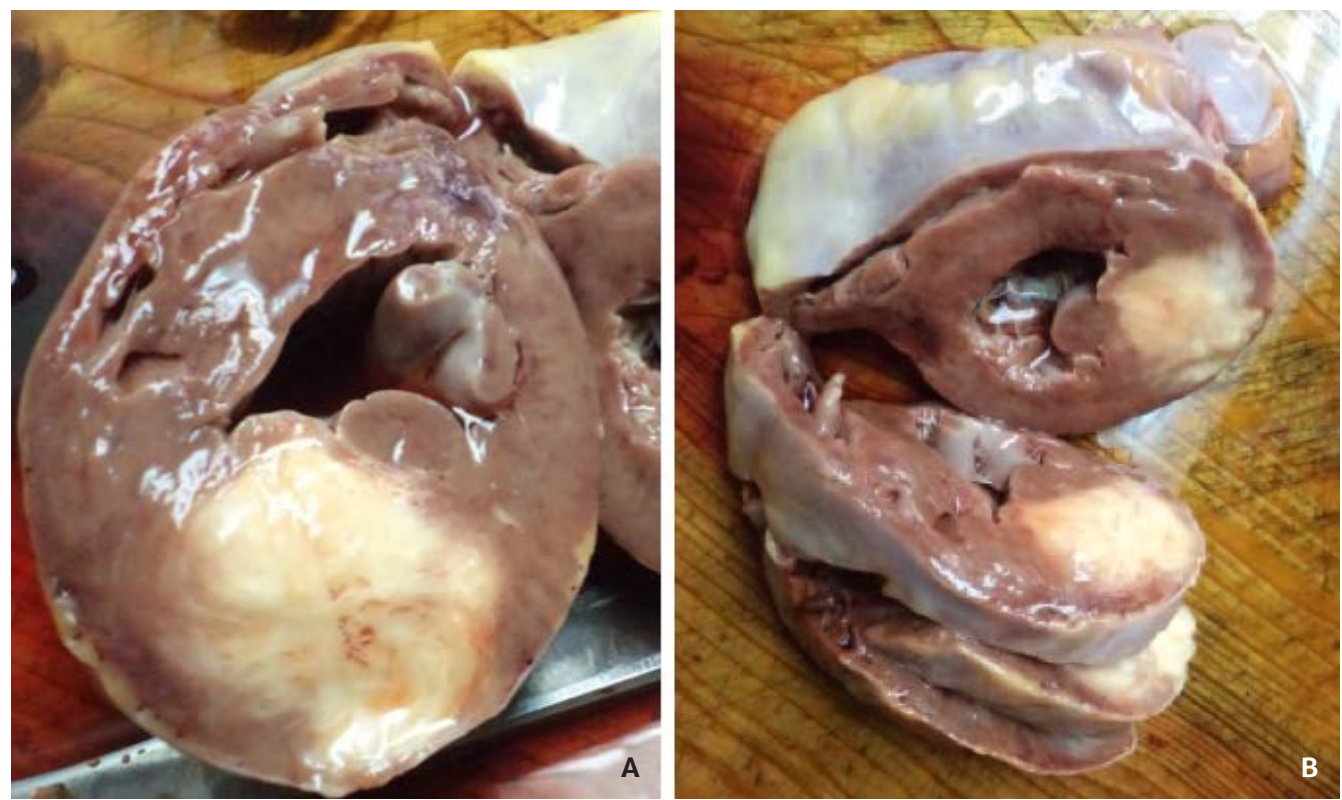

FIGURE 1. A - Section through the lateral wall of the left ventricle replaced by a $5 \times 3 \times 3 \mathrm{~cm}$ whiteto-yellow tumor with fascicular appearance and increased consistency; B - Extension of the cardiac tumor mass from the base to the apex.

\section{CASE REPORT}

We present the case of a 10-year-old male child, from a rural environment, who woke up suddenly during the night accusing paroxysmal dyspnea. His parents immediately requested emergency help, but in the meantime, the child died at home. Anamnestic data revealed no other previous pathology, no previous medical treatment, and the patient did not accuse premonitory symptoms, not even during physical exercise (he practiced football as a hobby).

Being a sudden death at home, police officers were required to conduct a forensic autopsy. At the autopsy examination, the patient had a height of $134 \mathrm{~cm}$, with proportional muscular and fat tissue, marked peripheral cyanosis, and conjunctival hyperemia. The internal examination of the body revealed the following macroscopic morphopathological changes: leptomeningeal hyperemia, massive cerebral edema, multiple subpleural hypoxic patches, apical pulmonary atelectasis, edema, and pulmonary emphysema. The heart had $8 \times 9 \times 7 \mathrm{~cm}$, with smooth, transparent epicardial tissue, brown on the section, the lateral wall of the left ventricle being replaced by a $5 \times 3 \times 3 \mathrm{~cm}$ white-to-yellow lesion (Figure $1 \mathrm{~A}$ ), extending from the base to the apex, with a fascicular aspect and an increased consistency, infiltrating the epicardial tissue as well (Figure 1B). The ventricular walls had the following thickness: left ventricle $3 \mathrm{~cm}$, interventricular
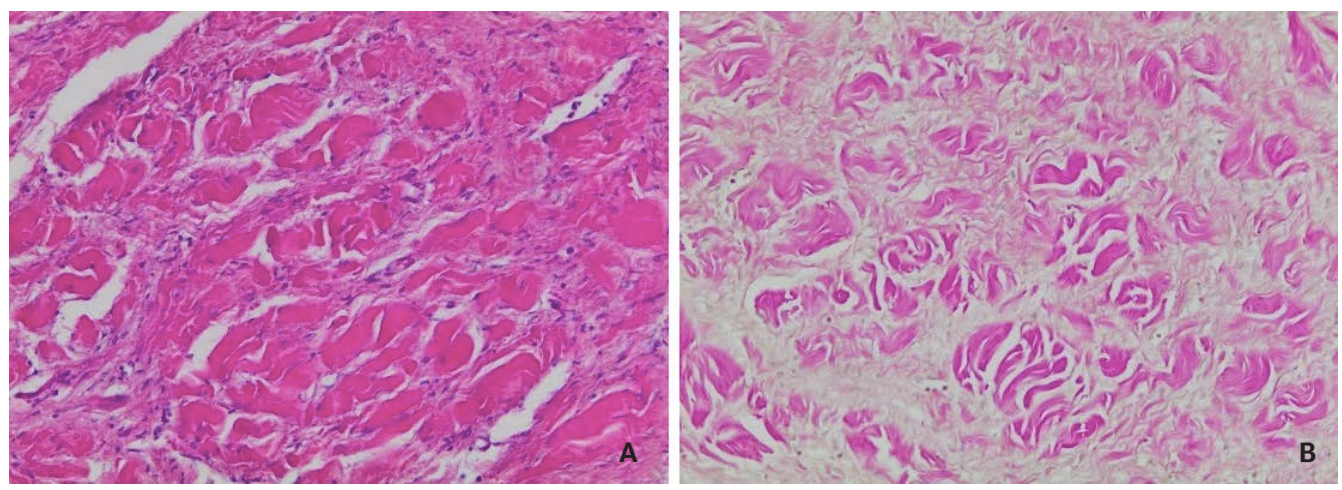

FIGURE 2. Histopathological features of the cardiac fibroma: fusiform cells without atypical features, most of them fibroblasts and bundles of collagen fibers, intensely eosinophilic on van Gieson staining. A - H\&E staining, 10x; B - van Gieson staining, 10x 
septum $1 \mathrm{~cm}$, right ventricle $0.3 \mathrm{~cm}$, with integral valve system, with flexible and elastic valves. The endocardium was glossy, smooth, transparent, and the coronary arteries were permeable, with smooth intima. The other organs had normal size and appearance.

The histopathological examination of the heart fragments revealed a large tumor that occupied almost the entire thickness of the ventricular wall, with imprecisely delimited edges. On hematoxylin-eosin staining, the tumor consisted of elongated, fusiform, monomorphic cells, predominantly fibroblasts, and numerous collagen bundles (Figure 2A), intensely eosinophilic on van Gieson staining (Figure $2 \mathrm{~B}$ ), the histologic appearance being very suggestive for a cardiac fibroma.

The histopathological examination of the lung fragments revealed focal acute edema, emphysema, and hyperemia.

\section{DISCUSSIONS}

Cardiac tumors are difficult to diagnose because the signs and symptoms may vary from total absence in one third of the cases, being discovered postmortem especially in cases with electrical conduction system involvement, to clinically manifested in the form of cardiac insufficiency with effort dyspnea, non-specific chest pain, cough, pulmonary systolic breathing. ${ }^{14-16}$ In the presented case, the child accused severe paroxysmal dyspnea, but only a few minutes before death.

Cardiac fibroma is a slow-growing, well-circumscribed, usually unique tumor with firm consistency and a diameter of 3 to $10 \mathrm{~cm}$, located in the ventricular myocardium, predominantly in the interventricular septum. Usually, radiological examination reveals the presence of cardiomegaly and, frequently, multiple isolated calcifications in the central area of the cardiac fibroma. ${ }^{14,15,17}$

Positive diagnosis can be confirmed by transthoracic and transesophageal echocardiography associated with contrast echocardiography for tumor vascular assessment, 3D echocardiography for spatial tumor characterization, and computed tomography or magnetic resonance imaging for the description of the shape, size, and texture. The precise diagnosis requires histopathological examination. ${ }^{12,18}$

The treatment of symptomatic cardiac fibroma consists in surgical resection as early as possible due to continuous tumor growth, risk of asystole and sudden death, and in cases where the tumor is very large, cardiac transplantation must be considered. ${ }^{3}$

\section{CONCLUSIONS}

Most cardiac tumors in children are rare and benign but are associated with high mortality and morbidity. Noninvasive examinations during childhood, such as cardiac ultrasound, even in the absence of heart failure symptoms, could detect early cardiac tumors, increasing early detection of this pathology, and decreasing the risk of sudden death in children. Therefore, applying of an early optimal management will reduce the risk of heart failure and sudden death at a young age.

\section{CONFLICT OF INTEREST}

None to declare.

\section{REFERENCES}

1. Murphy JG, Scott Wright R. Cardiac tumors. In: Mayo Clinic Cardiology. X: Mayo Clinic Scientific Press, 2007; p. 1027-1033.

2. McManus B, Lee $H$. Primary tumors of the heart. In: Braunwald's Heart Disease: A Textbook of Cardiovascular Medicine, 8th ed. Sauders Elsevier, 2008; p.1815-1828.

3. Ginghină C. Mic tratat de cardiologie. Bucharest: Editura Academiei Române, 2010; p. 737-747.

4. Sheppard MN, Angeli A, Raad M, Saveliera I. Tumors of the Heart. In: The ESC Textbook of Cardiovascular Medicine, 1st ed. X: Blackwell Publishing, 2006; p. 535-551.

5. Burke A, Jeudy J, Virmani R. Cardiac tumors. In: E. Topol Textbook of Cardiovascular Medicine. 3rd ed. X: Lippincott Wilkins, 2007; p. 710-720.

6. Bulkley BH, Hutchins GM. Atrial myxomas: a fifty year review. Am Heart J. 1979;97:639-643.

7. Chan HS, Sonley MJ, Moes CA, Daneman A, Smith CR, Martin DJ. Primary and secondary tumours of childhood involving the heart, pericardium, and great vessels. A report of 75 cases and review of the literature. Cancer. 1985;56:825-836.

8. Simcha A, Wells BG, Tynan MJ, Waterston DJ. Primary cardiac tumours in childhood. Arch Dis Child. 1971;46:508-514.

9. Uzun O, Wilson DG, Vujanic GM, Parsons JM, Giovanni JC. Cardiac tumours in children. Orphanet J Rare Dis. 2007;2:11. doi: 10.1186/1750-1172-2-11.

10. Holley DG, Martin GR, Brenner JI. Diagnosis and management of fetal cardiac tumors: a multicenter experience and review of published reports. J Am Coll Cardiol. 1995;26:516-520.

11. Xu ZH, Wu QY, Li HY, Xue H, Zhang MK, Jin YQ. Surgical Treatment of large Left Ventricular Fibroma in children. Chinese Medical Journal. 2017;130:1737-1738. doi: 10.4103/0366-6999.209901.

12. Jha NK, Kiraly L, Tamas C, et al. Large cardiac fibroma and teratoma in children - case reports. J Cardiothorac Surg. 2015;10:38. doi: 10.1186/s13019-015-0242-9.

13. Burke A, Virmani R. Tumors of the heart and great vessels. In: Atlas of Tumor Pathology. 3rd series, fasc 16. Washington DC: Armed Forces Institute of Pathology, 1996.

14. Burke A, Rosado-de-Christenson M, Templeton PA, Virmani R. Cardiac fibroma: clinicopathologic correlates and surgical treatment. J Thorac Cardiovasc Surg. 1994;108:862-870. 
15. Parmley LF, Salley RK, Williams JP, Head GB. The clinical spectrum of cardiac fibroma with diagnostic and surgical considerations: noninvasive imaging enhances management. Ann Thorac Surg. 1988;45:455-465.

16. Păun R. Tratat de Medicină Internă. Bolile cardiovasculare, partea a III-a. Bucharest: Editura Medicală, 1992; p. 651-670.
17. Soler-Soler J, Romero-Gonzalez R. Calcified intramural fibroma of the left ventricle. Eur J Cardiol. 1975;3:71-73.

18. Varlamis GS, Chalemis Z, Haritandi A, Gerakaris L, Fotiades N, Vassilicos V. Primary Intramural Fibroma of the Left Ventricle with a Late Apparent Symptomatology. Hell J Cardiol. 2005;46:362-365. 